\title{
Perioperative C-reactive protein is associated with pain outcomes after major laparoscopic abdominal surgery: a retrospective analysis
}

This article was published in the following Dove Press journal:

Journal of Pain Research

\author{
Hey-Ran Choi' \\ In-Ae Song ${ }^{2}$ \\ Tak Kyu Oh ${ }^{2}$ \\ Young-Tae Jeon ${ }^{2}$ \\ 'Department of Anesthesiology and Pain \\ Medicine, Inje University Seoul Paik \\ Hospital, Seoul, South Korea; \\ ${ }^{2}$ Department of Anesthesiology and Pain \\ Medicine, Seoul National University \\ Bundang Hospital, Seongnam, South \\ Korea
}

Purpose: This study is aimed to investigate an association between perioperative C-reactive protein (CRP) levels and both opioid consumption and postoperative pain scores in postoperative days (PODs) in patients who underwent laparoscopic major abdominal surgery. We hypothesized that postoperative opioid requirements and numeric rating scale (NRS) pain scores would be positively associated with perioperative CRP levels.

Patients and method: Medical records from 4,653 patients who underwent a laparoscopic major abdominal surgery from January 2010 to December 2016 were retrospectively reviewed. Generalized linear regression analysis was used to identify the association of preoperative and postoperative CRP levels, and increase in CRP level (postoperative CRP level - preoperative CRP level) with postoperative pain outcomes during POD 0-3.

Results: An increase of $1 \mathrm{mg} \mathrm{dL}{ }^{-1}$ of postoperative CRP level was significantly associated with $1.4 \%$ increase morphine equivalent consumption [exponentiated regression (Exp) coefficient: $0.014,95 \%$ CI $(0.011,0.016), P<0.001]$, whereas preoperative CRP levels were not significantly associated with morphine equivalent consumption on POD $0-3 \quad(P=0.450)$. A $1 \mathrm{mg} \mathrm{dL}{ }^{-1}$ of increase in CRP level was significantly associated with $1 \%$ increase of morphine equivalent consumption [Exp coefficient: $0.010,95 \%$ CI $(0.008,0.012), P<0.001$ ] Postoperative CRP levels were positively associated with NRS pain scores on POD 1, POD 2 , and POD $3(P<0.001)$. Increases of CRP levels were also positively associated with NRS pain scores on POD 0, POD 1, POD2, and POD3 $(P<0.05)$.

Conclusion: These results suggest postoperative CRP levels and increases in CRP levels are positively associated with opioid consumption and higher pain scores after major laparoscopic abdominal surgery.

Keywords: analgesia, anesthesia, pain, postoperative, opioid analgesics, C-reactive protein, numeric rating scale

\section{Introduction}

Opium and opioids have been used since ancient times to relieve pain, which is one of the major signs of inflammation, ${ }^{1}$ and currently they are the most commonly used drug for pain relief. ${ }^{2}$ It has been shown that opioid-mediated analgesia is mainly elicited via activation of peripheral opioid receptors, ${ }^{3}$ and anti-inflammatory actions of opioids, in addition to their analgesic effects, are produced through attenuation of the release of excitatory proinflammatory neuropeptides from peripheral nociceptors. $^{3-5}$ However, it has also been reported that, in contrast to their anti-inflammatory actions, opioids interact with opioid receptors on the membranes
Department of Anesthesiology and Pain Medicine, Seoul National University Bundang Hospital, Gumi-ro 173 Beon-gil, Bundang-gu, Seongnam 13620, South Korea

Tel +8 23I 7877499

Fax +823I 7874063

Email airohtak@hotmail.com 
of immune cells and alter cytokine production, ultimately inducing a pro-inflammatory state. ${ }^{6}$ A clinically useful marker that reflects such opioid-induced pro-inflammatory actions is elevated $\mathrm{C}$-reactive protein (CRP). ${ }^{6,7}$

CRP is a protein produced by the liver, and its level increases in response to inflammation. ${ }^{8}$ Several studies have reported that CRP levels may be elevated in opioidinduced pro-inflammatory states. ${ }^{7,9,10}$ Moreover, a recent cohort study has reported that compared to non-opioid users, plasma CRP level was elevated in opioid users. ${ }^{11}$ Similarly, several lines of evidence suggest a correlation between opioid dosage and CRP level. In addition, associations between CRP levels and surgical stress and postoperative recovery have been recently reported. ${ }^{12}$ Accordingly, CRP levels may be associated with patients' postoperative opioid requirements and pain scores, and correlations may exist between perioperative CRP levels and an increase in CRP levels, and a patient's opioid analgesic requirements and severity of postoperative pain. However, there is only limited information available regarding these possible correlations.

Thus, the present study aimed to measure the association between perioperative CRP levels and postoperative opioid analgesic requirements and pain scores of patients who underwent major laparoscopic abdominal surgery. We hypothesized that patients' postoperative opioid requirements and pain scores would be positively associated with preoperative and postoperative CRP levels, and increases of CRP levels.

\section{Material and methods}

This retrospective cohort study was approved by the Institutional Review Board (IRB) of Seoul National University Bundang Hospital (approval number: B-1803/ 459-105, approval date: March 12, 2018). The need for informed consent was waived by the IRB owing to the retrospective nature of the study, and this study followed the Declaration of Helsinki in confidentiality of patient data. Demographic, clinical, and surgery-related information of patients was collected. All medical records were collected by a medical record technician who was blinded to the study.

\section{Patients}

The medical records of patients aged 20 years or older who received an elective major laparoscopic abdominal surgery from January 1, 2010 to December 31, 2016 were collected for retrospective analysis. A major laparoscopic abdominal surgery was defined as all laparoscopy-guided surgical procedures involving intraperitoneal organ resection lasting over $2 \mathrm{~h}$. However, simple appendectomy and cholecystectomy were excluded even if they lasted more than $2 \mathrm{~h}$. Since these major laparoscopic abdominal surgeries include a heterogeneous population, many cases were excluded to analyze a relatively homogenous population regarding postoperative pain outcomes. These exclusion criteria were as follows: 1) patients who underwent emergency surgery; 2) patients who underwent single-port laparoscopy; 3) patients who were released before postoperative day (POD) 3; 4) patients who underwent an additional surgery during POD $0-3 ; 5)$ patients who needed intraoperative open conversion; and 6) patients who received continuous infusion of remifentanil or dexmedetomidine for pain control or sedation in the intensive care unit (ICU) on POD 0-3. No patients received continuous infusion of remifentanil or dexmedetomidine in the ward during POD $0-3$; all patients requiring sedation in the postoperative period were admitted to ICU after surgery.

Surgical resection of major intraperitoneal organs (liver, ${ }^{13}$ stomach, ${ }^{14}$ colon and rectum, ${ }^{15}$ and pancreas ${ }^{16}$ ) were performed by experienced surgical teams during the study period. For this study, surgeries were divided into five groups according to the main resected organ during surgery: upper gastrointestinal tract (stomach, duodenum, and small bowel); lower gastrointestinal tract (colon and rectum); hepatobiliary-pancreas-spleen; uterus-ovary; and prostate-kidney-bladder.

\section{Anesthesia and analgesia for major laparoscopic abdominal surgery}

All patients were anesthetized using two methods: one is remifentanil-inhalation agent (desflurane or sevoflurane) balanced anesthesia, and the other is total intravenous anesthesia (TIVA) with remifentanil-propofol.

Most patients received intravenous (IV) patient-controlled analgesia (PCA) on POD 0-2 after surgery. IV PCA was prepared with 8-12 mcg of fentanyl per $1 \mathrm{~mL}$ of normal saline (total $100 \mathrm{ml}$ ) and set at a background infusion rate of $0.8-1.2 \mathrm{~mL} \mathrm{~h}^{-1}$ and bolus dose of $0.5-1.5 \mathrm{~mL}$ depending on the patient's underlying painful conditions and age. Additional opioid analgesics (eg, oxycodone, morphine, and fentanyl) were prescribed for most patients based on the physician's prescription and the patients' need. Adjuvant analgesics (acetaminophen and ketorolac) were also used for additional pain control. In general, local anesthetic infiltration into the wound sites was not performed during the study period. 


\section{Collection of perioperative CRP data}

At the institution, CRP level $\left(\mathrm{mg} \mathrm{dL}^{-1}\right)$ is measured for patients undergoing elective surgery as part of the preoperative routine laboratory test within one month prior to the surgery. We defined this CRP level as the preoperative CRP. A patient's CRP level is also measured during POD 0-3 after surgery, depending on the type of surgical procedure the patient received and the surgeon's decision. The highest CRP level measured during POD 0-3 after surgery was defined as the postoperative CRP level. The difference between the postoperative CRP and preoperative CRP levels was defined as the increase of CRP.

\section{Postoperative pain outcomes on POD 0-3}

Pain scores were measured every $4-6 \mathrm{~h}$ at least 4 times a day on a numeric rating scale (NRS), with scores ranging from 0 to 10 , by registered nurses. The mean NRS pain scores obtained on POD $0,1,2$, and 3 were defined as the NRS pain score of the corresponding POD (POD 0, 1, 2, and 3). The total amount of opioid used, including the POD 0-3 IV PCA and additional opioid analgesics, was measured and summed up using oral morphine equivalent consumption (mg). A standard conversion ratio was used for the conversion and calculation. ${ }^{17}$ The data on the amount of oral acetaminophen (mg) and IV ketorolac (mg) used during POD 03 were additionally collected (Table S1).

\section{Outcome}

This study aimed to measure the associations between preoperative, postoperative, and increase of CRP levels and patients' postoperative pain outcome (morphine equivalent consumption in $0-3$, NRS pain score on POD 0-3, and adjuvant analgesics use on POD 0-3) following a major laparoscopic abdominal surgery. Additionally, we investigate whether this association was different according to anesthetic management (inhalation or TIVA)

\section{Statistical analysis}

The baseline characteristics of the patients are presented either as a number with percentage or mean value with SD. Restricted cubic splines (RCSs) were used to assess the log odds of morphine equivalent consumption on POD $0-3$ according to the patients' preoperative, postoperative, and increase of CRP levels. First, we examined the normality of distribution in dependent variables, such as morphine equivalent consumption, NRS on POD 0-3, acetaminophen consumption, and ketorolac consumption, by Kolmogorov-Smirnov test. After confirming that these variables did not follow a normal distribution, we decided to perform generalized linear regression analysis. In this generalized linear regression model, a gamma distribution was assumed for the dependent variable (morphine equivalent consumption), and a log link function was used. In this multivariate generalized linear regression analysis, all covariates were included for adjustment. Multicollinearity among variables was taken into account, and we established two multivariate generalized linear regression models, one for preoperative and postoperative CRP levels and the second for increase in CRP (postoperative CRP - preoperative CRP). In addition, another multivariate generalized linear regression analysis was performed for six postoperative outcomes (NRS pain score on POD 0-3, acetaminophen, and ketorolac use on POD 0-3) as dependent variables using the same manner. Additionally, we performed two subgroup analyses according to anesthetic management for major laparoscopic abdominal surgery (TIVA and inhalation group). The results of each analysis are presented as exponentiated regression (Exp) coefficients and 95\% CI. All data were analyzed using IBM SPSS 24.0 (IBM Corp., Armonk, NY, USA) and statistical significance was set at $P<0.05$. For the subgroup analysis (TIVA and inhalation group), we performed Bonferroni correction to control type 1 error in multiple comparisons, ${ }^{18}$ and a Bonferroni-corrected $P<0.025$ was considered to indicate statistical significance.

\section{Results}

A total of 20,800 patients underwent laparoscopy guided surgical procedures from January 2010 to December 2016. Of those patients, the following patients were excluded from the analysis: 1) patients under 20 years of age $(856)$; 2) patients who underwent emergency surgery $(1,053)$; 3) patients who underwent single port laparoscopy $(1,390)$; 4) surgical procedures under $2 \mathrm{~h}(9,571) ; 5)$ patients who received continuous infusion of remifentanil or dexmedetomidine in the ICU on POD 0-3 (343); 6) patients who were released within 3 days after surgery (8); 7) patients who underwent additional procedures during POD 0-3 (25); 8) patients who needed intraoperative open conversion (42); 9) patients who underwent a simple appendectomy or cholecystectomy $>2 \mathrm{~h}$ (96); and 10) patients with missing or incomplete medical record regarding CRP $(2,763)$. The final sample of 4,653 patients was included in the analysis (Figure 1). The characteristics of 


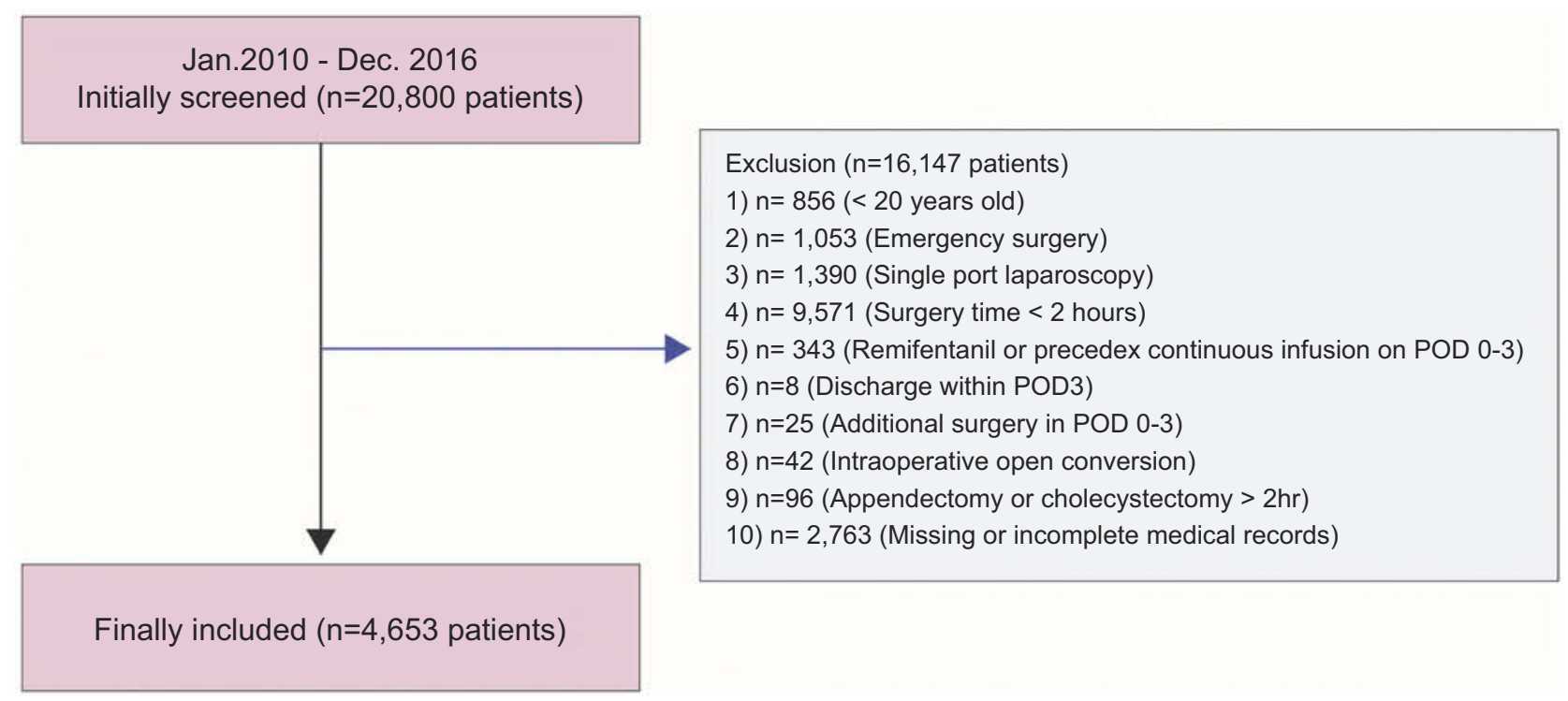

Figure I Flowchart for patient selection; 16,147 patients were excluded in the final analysis due to 10 causes. Abbreviation: POD, postoperative day.

these patients are shown in Table 1. The mean (SD) preoperative CRP level $\left(\mathrm{mg} \mathrm{dL}^{-1}\right)$, the mean postoperative CRP level, and the increase of CRP level were 3.5 (5.0), 9.7 (5.6), and 6.2 (6.6), respectively.

\section{Morphine equivalent consumption on POD 0-3}

Log odds of morphine equivalent consumption on POD 0-3 by preoperative CRP (A), postoperative CRP (B), and increase of CRP (C) levels are plotted as RCS in Figure 2. Log odds of morphine equivalent consumption by preoperative CRP levels first decreases and then increases, whereas log odds of morphine equivalent consumption by postoperative CRP levels and increase of CRP levels gradually increase with increasing level of CRP.

The results of multivariate generalized linear regression analysis including all covariates are shown in Table 2. In multivariate model 1 , an increase of $1 \mathrm{mg} \mathrm{dL}^{-1}$ of postoperative CRP level was significantly associated with an $1.4 \%$ increase morphine equivalent consumption [Exp coefficient: 0.014 , 95\% CI (0.011, 0.016), $P<0.001$ ], whereas preoperative CRP levels were not significantly associated with morphine equivalent consumption on POD $0-3 \quad(P=0.450)$. In multivariate model 2 , an $1 \mathrm{mg} \mathrm{dL}{ }^{-1}$ increase of CRP level was significantly associated with an $1.0 \%$ increase morphine equivalent consumption [Exp coefficient: $0.010,95 \%$ CI $(0.008,0.012), P<0.001]$.

\section{NRS pain score on POD $0-3$ and adjuvant analgesics use on POD 0-3}

The results of multivariate generalized linear regression analysis of NRS pain scores on POD 0-3 and acetaminophen and ketorolac use on POD 0-3 are shown in Table 3. Postoperative CRP levels were positively associated with NRS pain scores on POD 1 [Exp coefficient: $0.003,95 \%$ CI $(0.001,0.004), P<0.001]$, NRS pain scores on POD 2 [Exp coefficient: $0.006,95 \%$ CI $(0.004,0.007), P<0.001$ ], and NRS pain scores on POD 3 [Exp coefficient: 0.007, 95\% CI $(0.005,0.009), P<0.001]$. Increase of CRP levels were positively associated with NRS pain scores on POD 0 [Exp coefficient: $0.001,95 \%$ CI $(0.000,0.003)$, $P=0.049$ ], POD 1 [Exp coefficient: $0.002,95 \%$ CI (0.001, 0.003), $P<0.001$ ], POD2 [Exp coefficient: 0.004, 95\% CI $(0.002,0.005), P<0.001]$, and POD3 [Exp coefficient: $0.004, \quad 95 \%$ CI $(0.002, \quad 0.005), \quad P<0.001]$. Preoperative and postoperative CRP, and increase of CRP levels were not significantly associated with acetaminophen and ketorolac use on POD $0-3(P>0.05)$.

\section{Subgroup analysis according to anesthetic management}

The results of multivariate generalized linear regression analysis for morphine equivalent $(\mathrm{mg})$ consumption in POD 0-3 according to anesthetic management are presented in Table 4. A $1 \mathrm{mg} \mathrm{dL}{ }^{-1}$ increase of postoperative CRP is associated with increase of morphine 
Table I Characteristics of patients who received major laparoscopic abdominal surgery in 2010-2016

\begin{tabular}{|c|c|c|}
\hline Variables & Total $(n=4,653)$ & Mean (SD) \\
\hline $\begin{array}{l}\text { Age, year } \\
\text { Body mass index, } \mathrm{kg} \mathrm{m}^{-2} \\
\text { Sex: male/female } \\
\text { Preoperative comorbidites } \\
\text { ASA class } \\
\text { I } \\
2 \\
\geq 3 \\
\text { Hypertension } \\
\text { Diabete mellitus } \\
\text { Ischemic heart disease } \\
\text { Cerebrovascular disease } \\
\text { Chronic kidney disease } \\
\text { Cancer }\end{array}$ & $\begin{array}{l}2,950 / 1,703(63.4 \% / 36.6 \%) \\
1,813(39.0 \%) \\
2,658(57.1 \%) \\
182(3.9 \%) \\
1,463(31.4 \%) \\
722(15.5 \%) \\
210(4.5 \%) \\
130(2.8 \%) \\
68(1.5 \%) \\
3,924(84.3 \%)\end{array}$ & $\begin{array}{ll}60.1 & (12.7) \\
24.1 & (3.4)\end{array}$ \\
\hline $\begin{array}{l}\text { Information regarding surgical procedures } \\
\text { Surgery time, min } \\
\text { Mainly resected organ during surgery } \\
\text { Upper gastrointestinal tract } \\
\text { Lower gastrointestinal tract } \\
\text { Hepato-biliary-panreas-spleen } \\
\text { Uterus-ovary } \\
\text { Prostate-kidney-bladder } \\
\text { Propofol based intravenous anesthesia } \\
\text { Intraoperative magnesium sulfate infusion } \\
\text { Length of hospital stay after surgery, day } \\
\text { Years at surgery } \\
2010-2012 \\
2013-2014 \\
2015-2016\end{array}$ & $\begin{array}{l}200.1(69.8) \\
2,152(46.2 \%) \\
I, 920(41.3 \%) \\
474(10.2 \%) \\
32(0.7 \%) \\
75(1.6 \%) \\
735(15.8 \%) \\
387(8.3 \%) \\
\\
I, 287(27.7 \%) \\
I, 254(27.0 \%) \\
2, I 12(45.4 \%)\end{array}$ & $7.7(7.0)$ \\
\hline $\begin{array}{l}\text { Postoperative analgesics consumption on PODs 0-3 } \\
\text { Oral morphine equivalent consumption, } \mathrm{mg} \\
\text { Acetaminophen, } \mathrm{mg} \\
\text { Ketorolac, } \mathrm{mg}\end{array}$ & & $\begin{array}{l}592.20(282.39) \\
336.73(785.55) \\
14.10(106.01)\end{array}$ \\
\hline $\begin{array}{l}\text { Numeric rating scale, pain score } \\
\text { POD } 0 \\
\text { POD I } \\
\text { POD } 2 \\
\text { POD } 3\end{array}$ & & $\begin{array}{l}5.4(1.5) \\
4.6(1.1) \\
3.8(1.0) \\
3.2(1.0)\end{array}$ \\
\hline $\begin{array}{l}\text { Preoperative CRP, } \mathrm{mg} \mathrm{dl}^{-1} \\
\text { Postoperative CRP, } \mathrm{mg} \mathrm{dl}^{-1} \\
\text { Increase of CRP, } \mathrm{mg} \mathrm{dl}\end{array}$ & & $\begin{array}{l}3.5(5.0) \\
9.7(5.6) \\
6.2(6.6)\end{array}$ \\
\hline
\end{tabular}

Note: Presented as number with percentage or mean value with SD.

Abbreviations: SD, standard deviation; ASA, American Society of Anesthesiologists; POD, postoperative day; CRP, C-reactive protein.

equivalent consumption on POD $0-3$ in both inhalation group [Exp coefficient: $0.012,95 \%$ CI $(0.009,0.015)$, $P<0.001$ ] and TIVA group [Exp coefficient: $0.010,95 \%$ CI $(0.003,0.017), P=0.004]$. A $1 \mathrm{mg} \mathrm{dL}{ }^{-1}$ increase of
CRP is associated with increase of morphine equivalent consumption on POD $0-3$ in only the inhalation group [Exp coefficient: $0.011, \quad 95 \%$ CI $\quad(0.008,0.013)$, $P<0.001]$. 


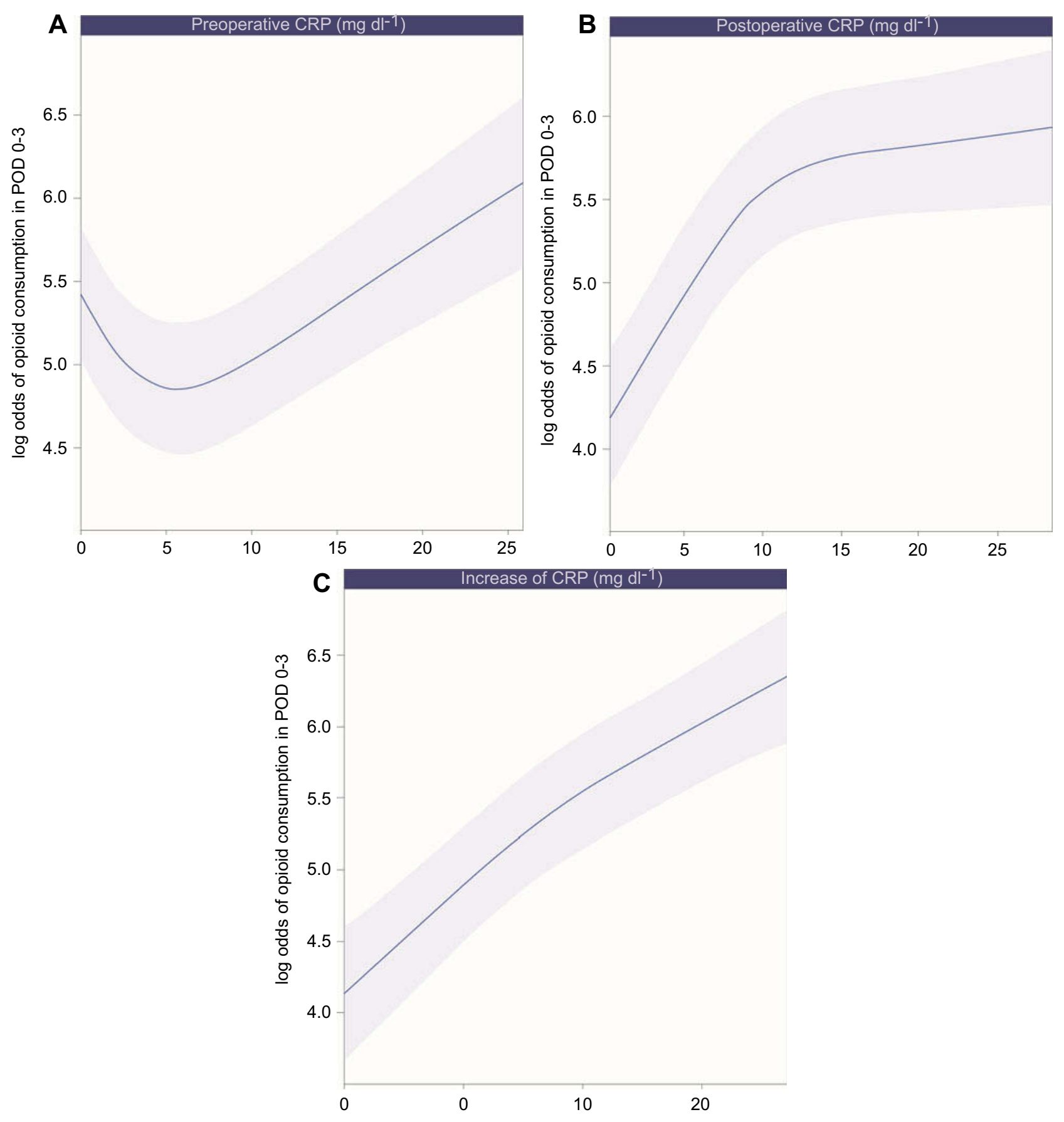

Figure 2 Relationship between morphine equivalent consumption on POD 0-3, and preoperative CRP (A), postoperative CRP (B), and increase of CRP (C) levels. Increase of CRP ( $\mathrm{mg} \mathrm{dL}^{-1}$ ): postoperative CRP - preoperative CRP.

Abbreviations: POD, postoperative day; CRP, C-reactive protein.

\section{Discussion}

The present study showed that morphine equivalent consumption on POD 0-3 following a major laparoscopic abdominal surgery is positively associated with postoperative CRP and an increase of CRP levels. The patients' NRS pain scores were also positively associated with postoperative CRP levels (on POD 1-3) and increase of CRP levels (on POD 2-3). These results not only add to the findings of previous studies that showed CRP level is a clinical marker related to postoperative recovery, ${ }^{12,19}$ but also show CRP level may reflect postoperative pain outcome. 
Table 2 Multivariate generalized linear regression analysis for morphine equivalent $(\mathrm{mg})$ consumption in POD 0-3 after major laparoscopic abdominal surgery in 2010-2016

\begin{tabular}{|c|c|c|}
\hline Variables & Exp. Coefficient $(95 \% \mathrm{Cl})$ & $P$-value \\
\hline Age, year & $-0.010(-0.011,-0.008)$ & $<0.001$ \\
\hline Sex: male (vs Female) & $0.114(0.086,0.141)$ & $<0.001$ \\
\hline Body mass index, $\mathrm{kg} \mathrm{m}^{-2}$ & $0.018(0.014,0.022)$ & $<0.001$ \\
\hline \multicolumn{3}{|l|}{ ASA } \\
\hline 2 (vs I) & $0.005(-0.028,0.038)$ & 0.762 \\
\hline$\geq 3$ (vs I) & $0.036(-0.040,0.112)$ & 0.350 \\
\hline \multicolumn{3}{|l|}{ Preoperative Comorbidity } \\
\hline Hypertension & $0.008(-0.025,0.042)$ & 0.622 \\
\hline Diabetes mellitus & $0.006(-0.032,0.045)$ & 0.740 \\
\hline Ischemic heart disease & $0.016(-0.048,0.080)$ & 0.618 \\
\hline Cerebrovascular disease & $-0.018(-0.098,0.061)$ & 0.650 \\
\hline Chronic kidney disease & $-0.076(-0.184,0.031)$ & 0.164 \\
\hline Cancer & $0.116(0.078,0.154)$ & $<0.001$ \\
\hline Surgery time, $\min$ & $0.001(0.001,0.00 I)$ & $<0.001$ \\
\hline \multicolumn{3}{|l|}{ Mainly resected organ during surgery } \\
\hline Lower gastrointestinal tract (vs UGI tract) & $0.086(0.057,0.116)$ & $<0.001$ \\
\hline Hepato-biliary-panreas-spleen (vs UGI tract) & $-0.373(-0.42 I,-0.325)$ & $<0.001$ \\
\hline Uterus-ovary (vs UGI tract) & $-0.623(-0.789,-0.457)$ & $<0.001$ \\
\hline Prostate-kidney-bladder (vs UGI tract) & $-0.210(-0.316,-0.105)$ & $<0.001$ \\
\hline Propofol based intravenous anesthesia & $-0.106(-0.150,-0.062)$ & $<0.001$ \\
\hline Intraoperative magnesium sulfate infusion & $0.065(-0.00 \mathrm{I}, 0.132)$ & 0.054 \\
\hline \multicolumn{3}{|l|}{ Years of surgery } \\
\hline $2013-2014$ (vs 2010-20I2) & $0.171(0.136,0.207)$ & $<0.001$ \\
\hline $2015-2016$ (vs 2010-2012) & $0.245(0.2 \mid 2,0.277)$ & $<0.001$ \\
\hline Preperative CRP, $\mathrm{mg} \mathrm{dl}^{-1}$ (model I) & $-0.001(-0.004,0.002)$ & 0.450 \\
\hline Postoperative CRP, $\mathrm{mg} \mathrm{dl}^{-1}$ (model I) & $0.014(0.011,0.016)$ & $<0.001$ \\
\hline Increase of CRP, $\mathrm{mg} \mathrm{dl}^{-1}$ (model 2) & $0.010(0.008,0.012)$ & $<0.001$ \\
\hline
\end{tabular}

Abbreviations: POD, postoperative day; Exp, exponentiated regression; Cl, confidence interval; ASA, American Society of Anesthesiologists; UGI, upper gastrointestinal tract; CRP, C-reactive protein.

The positive association between postoperative CRP and increase of CRP levels and the patients' opioid consumptions and pain scores on POD 0-3 may be attributed to several causes. First, postoperative CRP level is an indicator reflecting the invasiveness of a surgical procedure. ${ }^{20}$ Surgical stress from relatively more invasive procedures has been reported to induce more severe postoperative pain. ${ }^{21}$ Second, the elevated CRP level during the postoperative period is known to be closely associated with major postoperative complications, including infections. ${ }^{22,23}$ Postoperative pain may be both the cause and result of postoperative complication, ${ }^{24}$ and elevated CRP level may be a useful clinical marker reflecting this relationship. Furthermore, postoperative CRP could predict the severity of postoperative complications. ${ }^{25}$ Although our study focused on only laparoscopic surgery, it was reported that elevated CRP levels could be used as a marker for major postoperative complication in both open and minimally invasive surgery. ${ }^{23}$ Therefore, there was a possibility that postoperative complications affected severe postoperative pain with elevated CRP levels in this study.

From a different perspective, the association between postoperative opioid consumption and inflammation may be due to desensitization. Opioid receptors are members of the G-protein coupled receptor family, and the activation of an opioid receptor may decrease the activation of chemokine receptors. ${ }^{6,26}$ This desensitization may increase inflammatory cytokines, including CRP, and this process may be seen as a homeostatic response. In contrast, inflammation reaction from surgical stress may induce higher use of opioids. The patients with relatively higher surgical stress have a greater inflammatory reaction, and 
Table 3 Multivariate generalized linear regression for NRS pain score at rest on POD 0-3 and adjuvant analgesics use after major laparoscopic abdominal surgery in 2010-2016

\begin{tabular}{|c|c|c|}
\hline Variables & Exp. Coefficient (95\% Cl) & $P$-value \\
\hline \multicolumn{3}{|l|}{ NRS pain score on POD 0} \\
\hline Preperative CRP, $\mathrm{mg} \mathrm{dl}^{-1}$ (model I) & $-0.002(-0.003,0.000)$ & 0.085 \\
\hline Postoperative CRP, $\mathrm{mg} \mathrm{dl}^{-1}$ (model I) & $0.001(0.000,0.003)$ & 0.136 \\
\hline Increase of CRP, $\mathrm{mg} \mathrm{dl}^{-1}$ (model 2) & $0.001(0.000,0.003)$ & 0.049 \\
\hline \multicolumn{3}{|l|}{ NRS pain score on POD I } \\
\hline Preperative CRP, $\mathrm{mg} \mathrm{dl}^{-1}$ (model I) & $-0.002(-0.003,0.000)$ & 0.059 \\
\hline Postoperative CRP, $\mathrm{mg} \mathrm{dl}^{-1}$ (model I) & $0.003(0.001,0.004)$ & $<0.001$ \\
\hline Increase of CRP, $\mathrm{mg} \mathrm{dl}^{-1}$ (model 2) & $0.002(0.001,0.003)$ & $<0.001$ \\
\hline \multicolumn{3}{|l|}{ NRS pain score on POD 2} \\
\hline Preperative CRP, $\mathrm{mg} \mathrm{dl}^{-1}$ (model I) & $-0.001(-0.003,0.000)$ & 0.145 \\
\hline Postoperative CRP, mg dl ${ }^{-1}$ (model I) & $0.006(0.004,0.007)$ & $<0.001$ \\
\hline Increase of CRP, $\mathrm{mg} \mathrm{dl}^{-1}$ (model 2) & $0.004(0.002,0.005)$ & $<0.001$ \\
\hline \multicolumn{3}{|l|}{ NRS pain score on POD 3} \\
\hline Preperative CRP, $\mathrm{mg} \mathrm{dl}^{-1}$ (model I) & $0.000(-0.002,0.002)$ & 0.800 \\
\hline Postoperative CRP, mg dl ${ }^{-1}$ (model I) & $0.007(0.005,0.009)$ & $<0.001$ \\
\hline Increase of CRP, $\mathrm{mg} \mathrm{dl}^{-1}$ (model 2) & $0.004(0.002,0.005)$ & $<0.001$ \\
\hline \multicolumn{3}{|l|}{ Acetaminophen $(\mathrm{mg})$ use in POD 0-3 } \\
\hline Preperative CRP, $\mathrm{mg} \mathrm{dl}^{-1}$ (model I) & $-0.010(-0.018,0.003)$ & 0.129 \\
\hline Postoperative CRP, $\mathrm{mg} \mathrm{dl}^{-1}$ (model I) & $0.004(-0.001,0.008)$ & 0.058 \\
\hline Increase of CRP, $\mathrm{mg} \mathrm{dl}^{-1}$ (model 2) & $0.006(-0.003,0.015)$ & 0.157 \\
\hline \multicolumn{3}{|l|}{ Ketorolac use $(\mathrm{mg})$ in POD 0-3 } \\
\hline Preperative CRP, $\mathrm{mg} \mathrm{dl}^{-1}$ (model I) & $0.005(-0.013,0.024)$ & 0.555 \\
\hline Postoperative CRP, mg dl ${ }^{-1}$ (model I) & $-0.021(-0.039,0.007)$ & 0.251 \\
\hline Increase of CRP, $\mathrm{mg} \mathrm{dl}^{-1}$ (model 2) & $-0.016(-0.030,0.020)$ & 0.532 \\
\hline
\end{tabular}

Note: All covariates were included for adjustment in each multivariate generalized linear models.

Abbreviations: NRS, numeric rating scale; POD, postoperative day; Exp, exponentiated regression; Cl, confidence interval; CRP, C-reactive protein.

Table 4 Multivariate generalized linear regression analysis for morphine equivalent $(\mathrm{mg})$ consumption in POD 0-3 after major laparoscopic abdominal surgery in 2010-2016 according to anesthetic management

\begin{tabular}{|c|c|c|}
\hline Variables & Exp. Coefficient $(95 \% \mathrm{Cl})$ & $\mathbf{P} *$ \\
\hline \multicolumn{3}{|l|}{ Inhalation group $(n=3,9 \mid 8)$} \\
\hline Preperative CRP, $\mathrm{mg} \mathrm{dl}^{-1}$ (model I) & $-0.002(-0.005,0.001)$ & 0.185 \\
\hline Postoperative CRP, $\mathrm{mg} \mathrm{dl}^{-1}$ (model I) & $0.012(0.009,0.015)$ & $<0.001$ \\
\hline Increase of CRP, $\mathrm{mg} \mathrm{dl}^{-1}$ (model 2) & $0.011(0.008,0.013)$ & $<0.001$ \\
\hline \multicolumn{3}{|l|}{ Propofol based TIVA $(n=735)$} \\
\hline Preperative CRP, $\mathrm{mg} \mathrm{dl}^{-1}$ (model I) & $0.006(-0.003,0.014)$ & 0.180 \\
\hline Postoperative CRP, $\mathrm{mg} \mathrm{dl}^{-1}$ (model I) & $0.010(0.003,0.017)$ & 0.004 \\
\hline Increase of CRP, $\mathrm{mg} \mathrm{dl}^{-1}$ (model 2) & $0.005(-0.001,0.011)$ & 0.085 \\
\hline
\end{tabular}

Note: $* P<0.025$ was considered to indicate statistical significance after Bonferroni correction. All covariates were included for adjustment in each multivariate generalized linear models.

Abbreviations: POD, postoperative day; Exp, exponentiated regression; $\mathrm{Cl}$, confidence interval; CRP, C-reactive protein; TIVA, total intravenous anesthesia.

subsequently require a greater amount of opioid therapy. Lastly, opioids have been reported to induce proinflammatory reactions in in vitro studies, ${ }^{27,28}$ and a recent cross-sectional cohort study showed that an elevated CRP level is associated with opioid prescription. ${ }^{11}$ However, evidence on the association 
between opioid use and CRP level is still limited and this needs further investigation.

The results of subgroup analysis according to anesthetic management was also notable in this study. Although postoperative CRP level was associated positively with opioid consumption in POD $0-3$, increase of CRP was only associated with opioid consumption in the inhalation group. There was a possible reason that propofol-based TIVA suppresses the inflammatory response caused by surgery, compared to the balanced inhalation technique. ${ }^{29}$ This effect could be explained by the antiinflammatory effect of propofol. ${ }^{30}$ Considering that CRP increases in response to inflammation, ${ }^{8}$ increase of CRP during surgery could be attenuated in the propofol-based TIVA group, resulting in a lower effect on postoperative opioid consumption in the TIVA group than in the inhalation group.

The present study suggests the importance of postoperative management for patients who undergo major abdominal laparoscopic surgery. Patients with elevated CRP level during the postoperative period require a more careful pain control regimen. Thus, measuring postoperative CRP levels may help predict the possibility of severe pain in patients, and the use of regional analgesic techniques and adjuvant analgesics may be considered for patients with elevated postoperative CRP levels. Moreover, our findings suggest that a decrease in postoperative CRP levels is closely associated with postoperative pain intensity and opioid requirement of patients. Lastly, minimizing postoperative CRP elevation through more minimally invasive surgical procedures is important to reduce the length of stay ${ }^{12,23}$ and for lower postoperative pain.

This study has several limitations. First, like all retrospective cohort designs, this study may have involved selection bias. We tried to circumvent this limitation by having a medical record technician blinded to the study's purpose collect data used for the analysis. Second, the generalizability may be limited as this was a single-center study. Third, although fentanyl-based IV PCA was the main source of opioid analgesia, additional opioids were also used by the patients. Thus, a standard conversion ratio was needed for comparison of these analgesics. Fourth, a number of registered nurses were involved in collecting patients' pain score data over the 7-year study period. Therefore, the accuracy of NRS pain scores may not be completely guaranteed. Fifth, we did not evaluate the postoperative complication in this study, which could affect both postoperative CRP levels and opioid consumption. Lastly, we did not evaluate other inflammatory cytokines such as interleukin, procalcitonin, or tumor necrosis factors in this study. Nevertheless, our study demonstrates for the first time the association between postoperative CRP levels and postoperative pain outcome.

\section{Conclusion}

This study showed postoperative CRP and increase of CRP levels are positively associated with opioid consumption and higher pain scores after a major laparoscopic abdominal surgery.

\section{Author contributions}

H.R. Choi contributed to the study design, analyzed the data and drafted the first manuscript; T.K.O. contributed to the study design and provided critical revision of the manuscript; S.J. Kim, I.A. Song, and Y.T. Jeon contributed to the acquisition of data and provided critical revision of the manuscript; all authors have given final approval for the final version of the manuscript to be published and agree to be accountable for aspects of the work.

\section{Disclosure}

The authors report no conflicts of interest in this work.

\section{References}

1. Brownstein MJ. A brief history of opiates, opioid peptides, and opioid receptors. Proc Natl Acad Sci U S A. 1993;90(12):5391-5393.

2. Wu CL, Raja SN. Treatment of acute postoperative pain. Lancet. 2011;377(9784):2215-2225. doi:10.1016/S0140-6736(11)60245-6

3. Stein C. Targeting pain and inflammation by peripherally acting opioids. Front Pharmacol. 2013;4:123. doi:10.3389/fphar.2013. 00123

4. Endres-Becker J, Heppenstall PA, Mousa SA, et al. Mu-opioid receptor activation modulates transient receptor potential vanilloid 1 (TRPV1) currents in sensory neurons in a model of inflammatory pain. Mol Pharmacol. 2007;71(1):12-18. doi:10.1124/mol.106.026740

5. Stein C, Lang LJ. Peripheral mechanisms of opioid analgesia. Curr Opin Pharmacol. 2009;9(1):3-8. doi:10.1016/j.coph.2008.12.009

6. Rogers TJ, Peterson PK. Opioid G protein-coupled receptors: signals at the crossroads of inflammation. Trends Immunol. 2003;24(3):116-121.

7. Reece AS. High-sensitivity CRP in opiate addiction: relative and age-dependent elevations. Cardiovasc Toxicol. 2012;12(2):149-157. doi:10.1007/s12012-012-9154-2

8. Pepys MB, Hirschfield GM. C-reactive protein: a critical update J Clin Invest. 2003;111(12):1805-1812. doi:10.1172/JCI18921

9. Ghazavi A, Solhi H, Moazzeni SM, Rafiei M, Mosayebi G Cytokine profiles in long-term smokers of opium (Taryak). $J$ Addict Med. 2013;7(3):200-203. doi:10.1097/ADM.0b013e318 28baede

10. Nabati S, Asadikaram G, Arababadi MK, et al. The plasma levels of the cytokines in opium-addicts and the effects of opium on the cytokines secretion by their lymphocytes. Immunol Lett. 2013;152 (1):42-46. doi:10.1016/j.imlet.2013.04.003

11. Chopan M, Littenberg B. C-reactive protein and prescription opioid use. J Nat Sci. 2015;1(6):122. 
12. Cabellos Olivares M, Labalde Martinez M, Torralba M, Rodriguez Fraile JR, Atance Martinez JC. C-reactive protein as a marker of the surgical stress reduction within an ERAS protocol (Enhanced Recovery After Surgery) in colorectal surgery: A prospective cohort study. J Surg Oncol. 2018;117(4):717-724. doi:10.1002/jso.24909

13. Park JS, Han HS, Hwang DW, et al. Current status of laparoscopic liver resection in Korea. J Korean Med Sci. 2012;27(7):767-771. doi:10.3346/jkms.2012.27.7.767

14. Hwang SH, Park DJ, Jee YS, et al. Risk factors for operative complications in elderly patients during laparoscopy-assisted gastrectomy. J Am Coll Surg. 2009;208(2):186-192. doi:10.1016/j. jamcollsurg.2008.10.023

15. Kang SB, Park JW, Jeong SY, et al. Open versus laparoscopic surgery for mid or low rectal cancer after neoadjuvant chemoradiotherapy (COREAN trial): short-term outcomes of an open-label randomised controlled trial. Lancet Oncol. 2010;11(7):637-645. doi:10.1016/ S1470-2045(10)70131-5

16. Eom BW, Jang JY, Lee SE, Han HS, Yoon YS, Kim SW. Clinical outcomes compared between laparoscopic and open distal pancreatectomy. Surg Endosc. 2008;22(5):1334-1338. doi:10.1007/ s00464-007-9660-7

17. Mercadante S, Caraceni A. Conversion ratios for opioid switching in the treatment of cancer pain: a systematic review. Palliat Med. 2011;25(5):504-515. doi:10.1177/0269216311406577

18. Armstrong RA. When to use the Bonferroni correction. Ophthalmic Physiol Opt. 2014;34(5):502-508. doi:10.1111/opo.12131

19. Facy O, Paquette B, Orry D, et al. Diagnostic accuracy of inflammatory markers as early predictors of infection after elective colorectal surgery: results from the IMACORS study. Ann Surg. 2016;263 (5):961-966

20. Houten JK, Tandon A. Comparison of postoperative values for C-reactive protein in minimally invasive and open lumbar spinal fusion surgery. Surg Neurol Int. 2011;2:94. doi:10.4103/2152-7806.82575

21. Kehlet H. Surgical stress: the role of pain and analgesia. $\mathrm{Br}$ J Anaesth. 1989;63(2):189-195.

22. Ortega-Deballon P, Lagoutte N, Facy O. Inflammatory markers as predictors of surgical site infection after elective colorectal cancer surgery. Langenbecks Arch Surg. 2014;399(6):795-796. doi:10.1007/ s00423-014-1209-3
23. Straatman J, Cuesta MA, Tuynman JB, Veenhof A, Bemelman WA, van der Peet DL. C-reactive protein in predicting major postoperative complications are there differences in open and minimally invasive colorectal surgery? Substudy from a randomized clinical trial. Surg Endosc. 2017;32:2877-2885.

24. Liu SS, Wu CL. Effect of postoperative analgesia on major postoperative complications: a systematic update of the evidence. Anesth Analg. 2007;104(3):689-702. doi:10.1213/01.ane.0000255040. 71600.41

25. McSorley ST, Ramanathan ML, Horgan PG, McMillan DC. Postoperative C-reactive protein measurement predicts the severity of complications following surgery for colorectal cancer. Int J Colorectal Dis. 2015;30(7):913-917. doi:10.1007/s00384-0152229-3

26. Grimm MC, Ben-Baruch A, Taub DD, et al. Opiates transdeactivate chemokine receptors: delta and mu opiate receptor-mediated heterologous desensitization. J Exp Med. 1998;188(2):317-325.

27. Merighi S, Gessi S, Varani K, Fazzi D, Stefanelli A, Borea PA. Morphine mediates a proinflammatory phenotype via mu-opioid receptor-PKCvarepsilon-Akt-ERK1/2 signaling pathway in activated microglial cells. Biochem Pharmacol. 2013;86(4):487-496. doi:10.1016/j.bcp.2013.05.027

28. Peng X, Mosser DM, Adler MW, Rogers TJ, Meissler JJ Jr., Eisenstein TK. Morphine enhances interleukin-12 and the production of other pro-inflammatory cytokines in mouse peritoneal macrophages. J Leukoc Biol. 2000;68(5):723-728.

29. Ke JJ, Zhan J, Feng XB, Wu Y, Rao Y, Wang YL. A comparison of the effect of total intravenous anaesthesia with propofol and remifentanil and inhalational anaesthesia with isoflurane on the release of pro- and anti-inflammatory cytokines in patients undergoing open cholecystectomy. Anaesth Intensive Care. 2008;36 (1):74-78

30. Zheng X, Huang H, Liu J, Li M, Liu M, Luo T. Propofol attenuates inflammatory response in LPS-activated microglia by regulating the miR-155/SOCS1 pathway. Inflammation. 2018;41(1):11-19. doi:10.1007/s10753-017-0658-6 


\section{Supplementary material}

Table SI Equianalgesic opioid conversion table

\begin{tabular}{|l|l|l|}
\hline Opioid & Administration route & Dose equivalent to I0 mg of oral morphine (mg) \\
\hline Morphine & Oral & 10 \\
Morphine & Intravenous & 3.3 \\
Hydromorphone & Oral & 2 \\
Fentanyl & Intravenous & 0.03 \\
Oxycodone & Oral & 7 \\
Codeine & Oral & 80 \\
Tramadol & Oral & 40 \\
\hline
\end{tabular}

\section{Publish your work in this journal}

The Journal of Pain Research is an international, peer reviewed, open access, online journal that welcomes laboratory and clinical findings in the fields of pain research and the prevention and management of pain. Original research, reviews, symposium reports, hypothesis formation and commentaries are all considered for publication. The manuscript management system is completely online and includes a very quick and fair peer-review system, which is all easy to use. Visit http:// www.dovepress.com/testimonials.php to read real quotes from published authors 